\title{
تأثثر برنامج ترويحي مقترح لتحسين احدى مهارات الجمباز الايقاعي لطالبات المرحله الابتدائية
}

* * أميرة عبد المنعم الرشيلي

- مقدمة ومشكله البحث :

إن ممارسة الفرد للأنشطة المختلفة فى وقت فراغه سواء كانت رياضية أو إجتماعية أو فنية أو ثقافية أو خلوية تؤدى إلى إعتزاز الفرد وثقته بنفسه، فهو يتقاعل مع الآخرين ويشاركهم ويتبادل معهم الأفكار والآراء وينمى معارفه، كما تهدف الأنشطة الترويحية إلى تكوين الثخصية الإنسانية وصقلها من المراحل السنية المبكرة حتى تستمر مدى الحياة لتعمل على تتمية القدرات والتعبير عن النفس وقد تسهم فى أختبار المهنة فى المستقبل فضلاً عن التوازن الثخصى والتخلص من التوتز وضغوط لنهيه الحياة

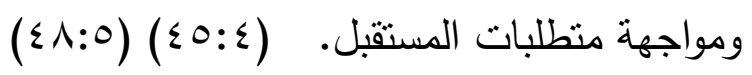

حيث يعمل الترويح من خلال هذه الأنشطة الترويحية على تطوير صحة الإنسان البدنية والعقلية والإجتماعية والنفسية، كما يسهم فى رفع الروح المعنوية

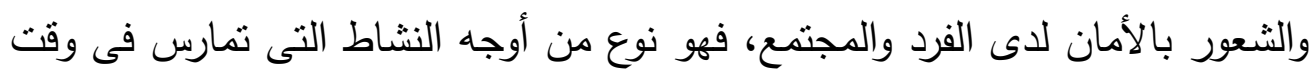
الفراغ والتى يختارها الفرد بدافع شخصى لممارستها والتى يكون من نواتجها إكتسابه العديد من القيم البدنية والخلقية والإجتماعية والمعرفية، فالترويح هو نشاط وخبرة وحالة

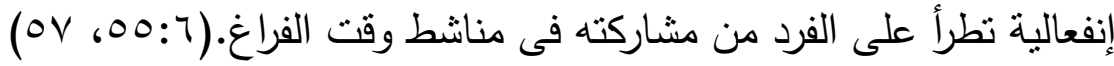

* باحثه دكتوراه بقم الادارة والترويح، كلية التربية الرياضية اسوان، جامعة اسوان. 
ويشير كمال عبد الرحمن درويش، أمين أنور الخولى ا...بام أن ممارسة أنشطة الترويح بمختلف نشطاته فى شكل منظم يطلق عليه البرامج الترويحية وهى

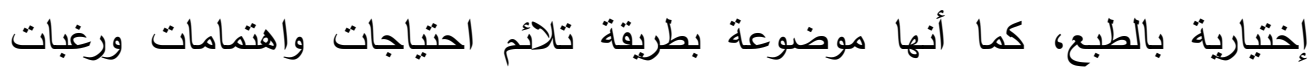
المشاركين، وتقدم برامج الترويح فى المؤسسات المعنية وفى المجتمع المحلى كالأندية ومراكز الثباب والمؤسسات التعليمية والجمعيات الإجتماعية، ويطلق على البرامج الترويحية مسميات مختلفة حسب نوع المؤسسة التى تقدم البرنامج ونوع النشاط فهناك

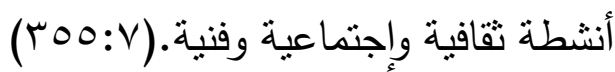

ويرى فيروف virouv (^...rم) أن الأنشطة الترويحية تزبد من دافعية الانجاز وتدعم السلوك التعليمي والاجتماعي ، فاستخدام الألعاب الحركية الترويحية التي تخص الخيال تسمح لهم بأسلوب شيق عند عرض معلوماتهم المتعلمة ( 17 $\left(10 \varepsilon_{6}\right) \vee A$ :

ويثير عبدالحق || بـ الي ان رياضه الجمباز من الرياضات ذات الاهميه الكبري في برامج التربيه الرياضيه والتي تعمل علي اثباع حاجات الثباب ،وتلائم مراحلهم العمريه المختلفه وهي منلها في ذلك منل اي نشاط فردي اخر، حيث تعمل علي نزويد الفرد بالمهارات والتى تستمر معه لممارستها في المستقبل ذلك انها تساهم بدرجه كبيره

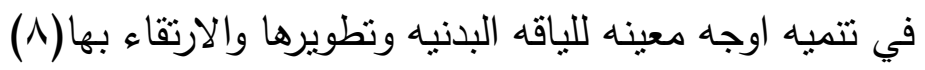

ويتطلب الجمباز الايقاعي درجه عاليه من المهاره الرياضيه تتضمن قدرات معينه يجب توافرها في اللاعبه منل المرونه،الرشاقه،القوه،الاتزان،مع مراعاه ان كل اداه تختلف في دئ متطلباتها عن الاخرى مما يتطلب من اللاعبه التوافق مابين اداء المهاره ومتطلبات الاداة.

وللوصول الي العالميه للاعبه الجمباز الايقاعي يجب ان تتوافر لديها الموهبه الطبيعيه،وقوه التحمل للتدريب الثاق ،هذا بالاضافه الي ان رياضه الجمباز الايقاعي تساعد علي تتميه الثخصيه بجانب جمال الاداء وقوه التاثير علي المشاهدين(9: (0) 
إن ما يحدث للفتيات ، وهذا ما اوضحته دراسة دراسة "ايمان جمال جابر مرغنى "

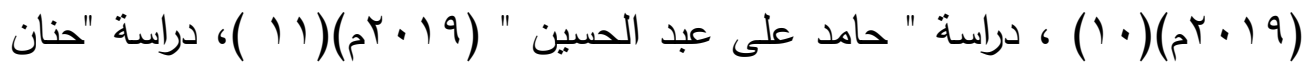

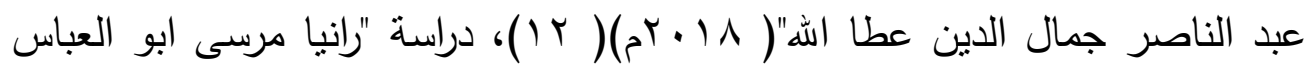

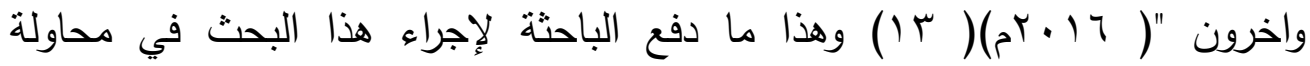

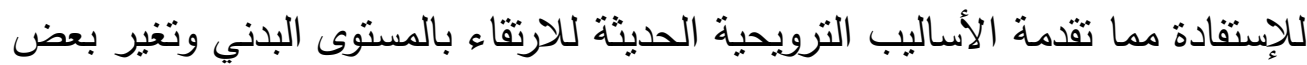
المفاهيم الخاطئة عن ممارسة رياضة الجمباز الايقاعي ومدى تخوف الطالبات من مشاركتهن في هذه الرياضة . - هدف البحث:

يهذف البحث الحالي الي تصميم برنامج ترويحي لتحسين احدى مهارات الجمباز الايقاعي (مهارتي الدحرجه الامامية،الوقوف على اليدين) للى طالبات المرحلة الابتدائية .

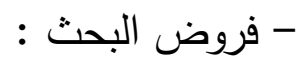
ا ـهناك فروق دالة أحصائيا بين القياس القبلى والبعدى على مستوى الصفات البدنية الخاصه برياضه الجمباز الايقاعي لعينة البحث لصالح القياس البعدي. r.هناك فروق دالة أحصائيا بين القياس القبلى والبعدى على احدى مهارات الجمباز

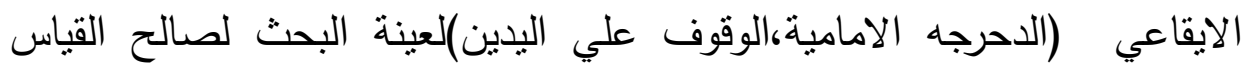

$$
\text { البعدي. }
$$

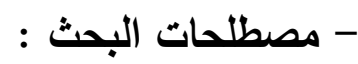

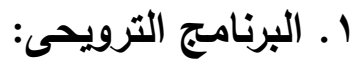
هو مجموعة من الأنشطة المنظمة والمختارة وفقاً لميول وحاجات وقدرات

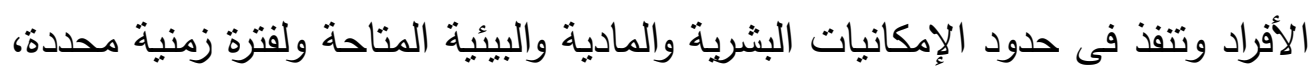
وتهدف أساسا إلى استثمار أوقات فراغهم بما يحقق لهم السعادة والرضا عن النفس ،

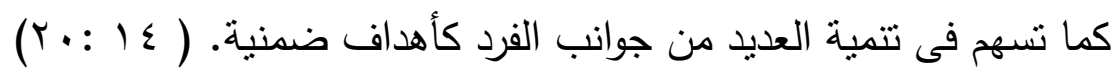

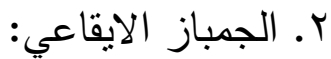


هي رياضه تنافسيه تتميز بالطابع الجمالي وبالتعبير العاطفي السار وتتكون عناصرها من الارتباط الفني الجميل للتمرينات الاساسيه والايقاعيه والحركات الاكروباتيه والرقص والباليه مع المصاحبه الموسيقيه التى تعبر اصدق تعبير عن جمال وتتاسق

$$
\text { وانسيابيه الحركات (r) }
$$

$$
\text { - }
$$

$$
\text { إجراءات البحث }
$$

استخدمت الباحثة المنهج التجريبي بنظام المجموعة الواحدة (قبلي وبعدي).

$$
\text { مجتمع البحث: }
$$

يمثنل مجتمـع البحـث طالبـات المرحلـة الإبتدائيـة المدرسـة التجريبيـه للغـات

\begin{tabular}{|c|c|c|}
\hline عدالإعدادية تلاميذ المرحلة & 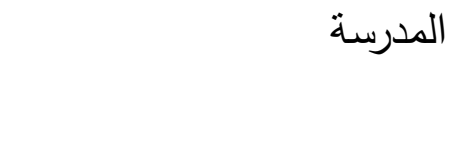 & 5 \\
\hline r & الصف الاول الابتدائي بنات & 1 \\
\hline ا ا تلمبذة & الصف الثاني الابتدائي بنات & r \\
\hline ع ا تلميذة & الصف الثالث الابتدائي بنات & r \\
\hline VT تلميذة & الإجمالي & \\
\hline
\end{tabular}

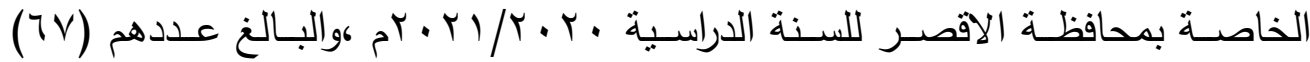
طالبه.

\section{جدول(1)}

توصيف مجتمع البحث 
عينة البحث:

قامت الباحثة باختيار عينة مكونة من (rr) تلميذة في المرحلة الابتدائية

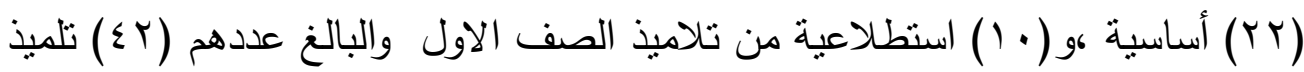

بالطريقة العمدية.

وتم اختيار عينة البحث وفقاً للخصائص والثروط الآتية:-

-طالبات في المرحلة الابتدائيه من الاناث .

- طالبات يرغبون بالمشاركة في البرنامج الترويحي.

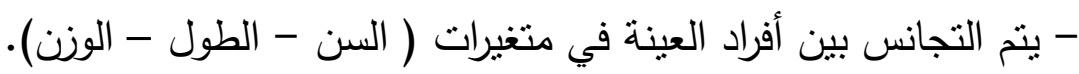

جدول (r)

\begin{tabular}{|c|c|c|}
\hline النسبة & العدد & البيان \\
\hline$\%$ or & r r تلميذ & العينة الأساسية \\
\hline$\%$ Y & ـ ا تلميذ & العينة الاستطلاعية \\
\hline$\% \vee 7$ & بr تلميذ & مجموع العينة \\
\hline$\% 1 \ldots$ & ب ع تلمبذ & إجمالي المجتمع \\
\hline
\end{tabular}

تجانس عينة البحث:

قامت الباحثة بإجراء التجانس بين أفراد العينة في بعض المتغيرات التي قد تؤثز علي المتغير التجريبي ،ويوضح جدول (r) تجانس أفراد العينة.

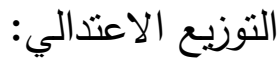




$$
\text { جدول (r) }
$$

المتوسط الحسابي والانحراف المعياري

اختبار كولمجروف سميرونوف في (متغيرات البحث) للعينة قيد البحث (ن= Y

\begin{tabular}{|c|c|c|c|c|c|}
\hline \multicolumn{2}{|c|}{ اختبار كولمجروف سميرونوف } & \multirow{2}{*}{ الانحراف } & \multirow{2}{*}{ الحتوسط الحسبي } & \multirow[b]{2}{*}{ المتغيرات } & \\
\hline مستوى الدلالة & الإحصائية & & & & \\
\hline. $.1 V$ & 1.11 & $\cdot . \wedge$. & IT.VT & 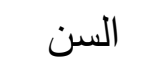 & 1 \\
\hline .94 & $.0 \leqslant$ & r.9. & 100.11 & الطول & r \\
\hline.$V V$ &. $.7 V$ & T.17 & rN.Tr & 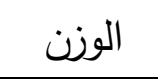 & r \\
\hline
\end{tabular}

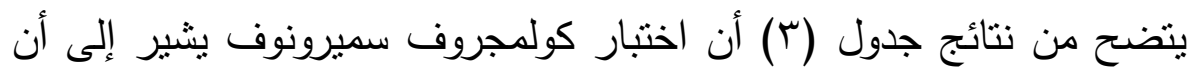

العينة تتبع التوزيع الطبيعي في متغيرات النمو قبد البحث حيث أن قيم اختبار

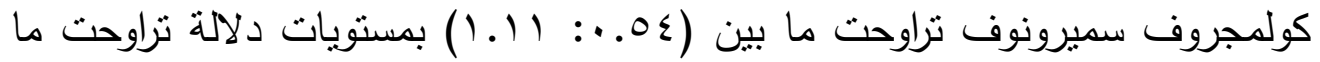

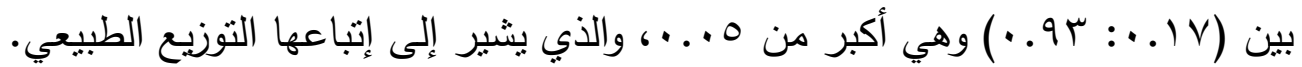

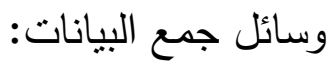

حددت الباحثة مجموعة من الأدوات والمقاييس الخاصة بتطبيق البرنامج •

(V) البرنامج الترويحي الرياضي المقترح وقد نم تصميمة من قبل الباحثة. مرفق البقدي القياسات المستخدمة في البحث:

- القياسات الخاصة بأفراد العينة: 1 - تحديد السن من خلال الاطلاع علي تواريخ الميلاد في السجلات الخاصة بالطالبات. r- تحديد الطول بالسنتيمتر من خلال استخدام الرستاميتر . r- تحديد الوزن بالكيلو جرام من خلال استخدام الميزان الطبي. 


\section{- وسائل تسجيل البيانات لأفراد العينة:}

من خلال استخدام استمارة تسجيل البيانات الثخصية (الاسم-السن-الطول-

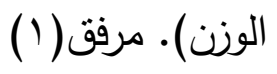

: أدوات خاصة بتطبيق البرنامج :

$$
\text { كرات طبية. }
$$

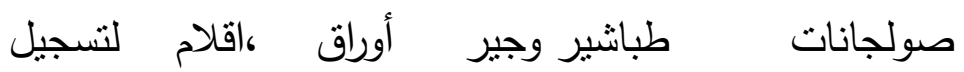

النتائج

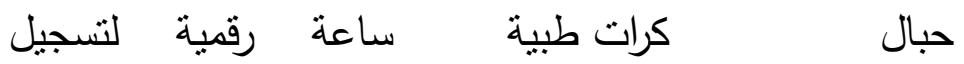

الوقت

الاراسة الاستطلاعية الاولي:

قامت الباحثة بعمل دراسة استطلاعية وذلك بهدف الوقوف علي مدي ملائمة المقياس للأهداف المراد معرفتها وقياس الصفات البدنية التى تخدم الجمباز الايقاعي كوقد تم تطبيق المقياس علي عينة قوامها (• ()طالبات من مجتمع البحث ومن خارج

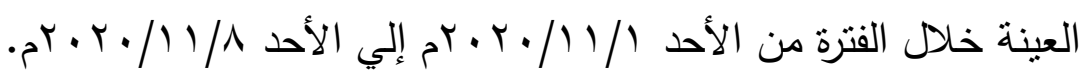

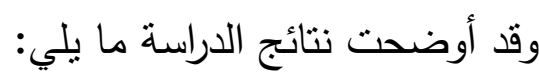
1- صلاحية المقياس المختار للاستخدام. r- سهولة الالعاب وتمثيلها لكل طالبة.

ب- توظيف البرنامج لخدمة الرياضهه من خلال تتميه الصفات الخاصه

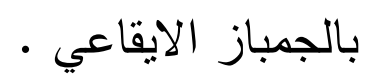

1- أسس وضع البرنامج الترويحي المقترح:

قامت الباحثة بتصميم برنامج ترويحي بما بتتاسب مـع قدرات واستعدادات عينة

البحث وطبيعة البيئة والإمكانات المتاحة، وقد راعت الباحثة/لآتي : 1- نتاسب الالعاب الصغيرة مع قدرات وخصائص عينة البحث. 


\section{r- التتوع والثمولية لمحتوي البرنامج الترويحي •}

r- مراعاة عوامل الأمن والسلامة للطالبات أثناء تطبيق البرنامج.

ء- الوضع في الاعتبار التدرج في الالعاب من السهل للصعب.

قامت الباحثة بعدل مسـح مرجعي الدراسـات - التي أتيحت - مثنل دراسـة دراسـة

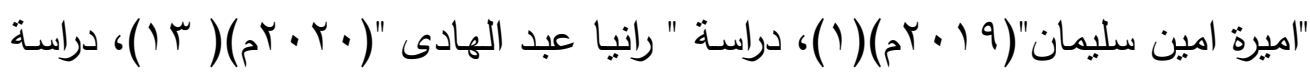

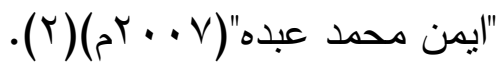

$$
\begin{aligned}
& \text { أ- الصدق : }
\end{aligned}
$$

\section{جدول (飞)}

دلالة الفروق بين متوسطي القياسين القبلي والبعدي في

الإختبارات البدنية قيد البحث

$(1 \leqslant=\dot{0})$

\begin{tabular}{|c|c|c|c|c|c|c|c|}
\hline \multirow{2}{*}{ قبمة"ت" } & \multirow{2}{*}{ التحسب } & \multicolumn{2}{|c|}{ القياس البعدي } & \multicolumn{2}{|c|}{ القباس القبلي } & \multirow{2}{*}{ وحدة } & \multirow[b]{2}{*}{ المتغير } \\
\hline & & الإنحراف & المتوسط الحسبي & الإنحراف & المتوسط الحسبي & & \\
\hline $0 .$. & $\% r \ldots$ &. $.7 r$ & $V .7 V$ &..$\wedge 7$ & $q . r$. & ثانية & رشاقه \\
\hline$\varepsilon . \wedge 9$ & $\% 97 . r$. & 7.79 & $r . . T V$ & & 1.01 & تكرار & مرونه \\
\hline 0.91 & $\begin{array}{c}17 \varepsilon .01 \\
\%\end{array}$ & 1. ro & L.Y & & 1.7. & سم & قوة \\
\hline
\end{tabular}

$r .17=(. .00)$

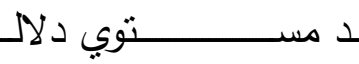

ع (ت)

قيمـــ

دال

يتضح من نتائج جدول (ع) وجود فروق دالة إحصائياً عند مستوى (0. . •) بين متوسطي درجات القياسين القبلي والبعدي في الصفات البدنية التى تستخدم لتحسين 
مهارات الجمباز الايقاعي قيد البحث لصالح متوسط درجات القياس البعدي، حيث تراوحت قيمة "ت" المحسوبة ما بين (اس.r: ب.9.9) ، كما تراوحت نسب التحسن ما

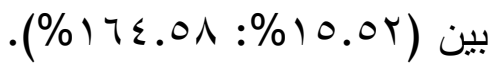

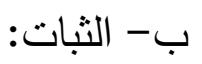

لإيجاد معامل الثبات استخدم الباحث طريقة تطبيق الاختبارات وإعادة التطبيق

على نفس العينة الاستطلاعية المستخدمة سابقاً في الصدق ،وجدول (0) يوضح ذلك.

$$
\text { جدول (•) }
$$

معامل الارتباط بين النطبيق وإعادة النطبيق لمهارات الجمباز الايقاعي قيد البحث

\begin{tabular}{|c|c|c|c|c|c|c|}
\hline \multirow{2}{*}{ قالمحسة "ر" } & \multicolumn{2}{|c|}{ إعادة التطبيق } & \multicolumn{2}{|c|}{ التطبيق } & \multirow{2}{*}{ القياس } & \multirow[b]{2}{*}{ المتغير } \\
\hline & الانحراف & الحتوسط الحسبي & الانحراف & الحستوسط الحسي & & \\
\hline. .91 & $\varepsilon . V V$ & $0 \wedge .0$. & $\varepsilon . \varepsilon)$ & $01 . .0$ & درجة & الدحرجه الاماميه \\
\hline$\cdot \vee \wedge \wedge$ & r.VV & Or.o. & $\varepsilon . T_{1}$ & $\varepsilon \wedge . .0$ & درجه & الوقوف علي اليدين \\
\hline
\end{tabular}

$$
(0=\dot{0})
$$

بتضح من جدول (0) أن معامل الارتباط بين القياسين الأول والثاني دال

إحصائيا في المقياس قيد البحث مما يدل على ثبات المقياس قبد البحث ،حيث أن الن قيمة معامل الارتباط (9^.9 • ) وهي أكبر من قيمة "ر " الجدولية عند مستوى (0. ). البرنامج الترويحي الرياضي المقترح:

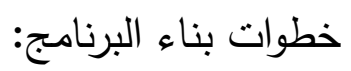

قبل البدء في خطوات بناء البرنامج كان لابد من تحديد هدف البرنامج العام

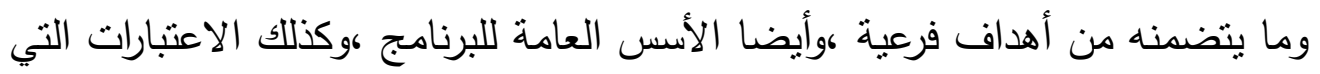
يجب مراعاتها عند تتفيذ البرنامج ونوضحها فيما يلي: 
- الهدف العام للبرنامج:

يهدف البرنامج المقترح إلي تعلم احدى مهارات الجمباز الايقاعي باسلوب

ممتع وغير ممل

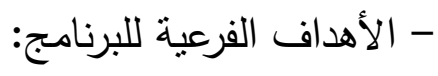

1- تحسين مستوي الطالبات في احدى مهارات الجمباز الايقاعي(الاحرجه

الاماميه،الوقوف على اليدين).

- الأسس العامة للبرنامج:

1- بناء البرنامج طبقا للأسس العلمية.

r- إتاحة الفرصة لاشتراك جميع الطالبات في وقت واحد.

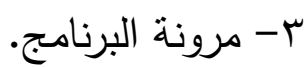

ع - قبول البرنامج للنطبيق العلمي.

0- مدة البرنامج ملائمة للهدف.

7- ملائمة البرنامج للمرحلة السنية.

V- ملائمة البرنامج للإمكانات المتاحة.

- الاعتبارات التي يجب مراعاتها عند تنفيذ البرنامج: 1- شرح الألعاب التمهيدية والصغيرة فبل بداية كل وحدة. r- يجب أن يحقق البرنامج الهدف الموضوع من أجله. ب- الاستعانة بوسائل الإيضاح كي تسهل عملية الأداء.

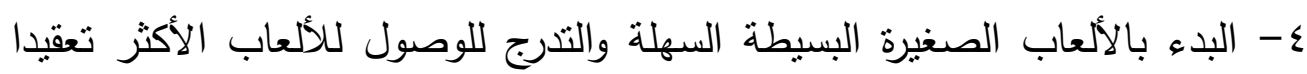
التي تخدم المهارات.

- مراعاة عوامل الأمن والسلامة عند التنفيذ. 7- ارتباط البرنامج بعملية التقويم. 


\section{الخطة الزمنية للبرنامج الترويحي الرياضي المقترح:}

قامت الباحثة بتصميم استمارة لاستطلاع رأي السادة الخبراء أثناء المقابلات الثخصية معهم تتضمن مجموعة من الأسئلة حول تحديد متغيرات الخطة الزمنية للبرنامج من حيث مدة نطبيق البرنامج ،وعدد الوحدات ،وعدد مرات التطبيق في مي ماتي الأسبوع ،وزمن الوحدة الكلي وكل جزء علي حدى. مرفق(0) وجدول (7) يوضح آراء السادة الخبراء حول متغيرات الخطة الزمنية.

\section{جدول(7)}

التكرار والنسبة المئوية لاستطلاع رأي الخبراء في منغيرات الخطة الزمنية

\begin{tabular}{|c|c|c|c|c|}
\hline \multicolumn{2}{|c|}{ رأي الخبراء } & \multirow{2}{*}{ المتغيرات } & \multirow{2}{*}{ عناصر الخطة } & \multirow{2}{*}{ r } \\
\hline النسبة \% & التكرار & & & \\
\hline$\% \wedge q$ & $\wedge$ & شهرين & \multirow{4}{*}{ الزمن الكلي للبرنامج } & \multirow{4}{*}{1} \\
\hline$\% \backslash 1$ & 1 & ثلاثة شهور & & \\
\hline$\%$. & · & أربعة شهور & & \\
\hline$\%$. & · & أخري تذكر & & \\
\hline$\% 1 \ldots$ & 9 & 7 ا وحدة & \multirow{4}{*}{ عدد الوحدات } & \multirow{4}{*}{ r } \\
\hline$\%$. & · & گ Y وحدة & & \\
\hline$\%$. & • & rس وحدة & & \\
\hline$\%$. & · & أخري تذكر & & \\
\hline$\% 1 \ldots$ & 9 & وحدتان & \multirow{4}{*}{ عدد الوحدات في الأسبوع } & \multirow{4}{*}{ r } \\
\hline$\%$. & · & ثلاث وحدات & & \\
\hline$\%$. & - & أربع وحدات & & \\
\hline$\%$. & - & أخري تذكر & & \\
\hline
\end{tabular}




\begin{tabular}{|c|c|c|c|c|}
\hline$\% 1 \ldots$ & 9 & مرة & \multirow{4}{*}{ عدد مرات تكرار الوحدة } & \multirow{4}{*}{$\varepsilon$} \\
\hline$\%$. & • & مرتان & & \\
\hline$\%$. & . & ثلاث مرات & & \\
\hline$\%$ & . & أخري تذكر & & \\
\hline$\%$ \%r & r & هم دقيقة & \multirow{4}{*}{ الزمن الكلي للوحدة } & \multirow{4}{*}{0} \\
\hline$\% \vee \wedge$ & V & 0 \ـ دقيقة & & \\
\hline$\%$. & . & • 7 دقيقة & & \\
\hline$\%$ & - & أخري تذكر & & \\
\hline$\% \backslash 1$ & 1 & 0 & \multirow{4}{*}{ زمن الجزء التمهيدي } & \multirow{4}{*}{7} \\
\hline$\% \wedge 9$ & $\wedge$ & • ا دقائق & & \\
\hline$\%$. & . & 1 دقيقة & & \\
\hline$\%$. & . & أخري تذكر & & \\
\hline$\% 1 \ldots$ & 9 & • r دقيقة & \multirow{4}{*}{ زمن الجزء الرئيسي } & \multirow{4}{*}{ V } \\
\hline$\%$ & . & • ـ دقيقة & & \\
\hline$\%$. & . & 0 \ـ دقيقة & & \\
\hline$\%$ & . & أخري تذكر & & \\
\hline$\% 1 \ldots$ & 9 & م دقائق & \multirow{4}{*}{ زمن الجزء الختامي } & \multirow{4}{*}{$\wedge$} \\
\hline$\%$. & . & • ا دقائق & & \\
\hline$\%$. & . & 10 دقيقة & & \\
\hline$\%$. & . & أخري تذكر & & \\
\hline
\end{tabular}

يتضح من جدول (T) والخاص بالتكرار والنسبة المئوية لاستطلاع رأي الخبراء في متغيرات الخطة الزمنية للبرنامج المقترح ومدي مناسبته لعينة البحث ،ومن خلال العرض السابق تم تحديد الإطار الزمني للبرنامج كما هو موضح في الجدول التالي: 
جدول ج)

الخطة الزمنية للبرنامج الترويحي الرياضي المقترح

\begin{tabular}{|c|c|c|}
\hline المتغيرات & عناصر الخطة & م \\
\hline شهرين & الزمن الكلي للبرنامج & 1 \\
\hline ا 17 وحدة & عدد الوحدات & r \\
\hline 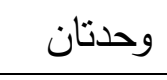 & عدد الوحدات في الأسبوع & r \\
\hline 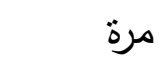 & عدد مرات تكرار الوحدة الواحدة & $\varepsilon$ \\
\hline 0 & الزمن الكلي للوحدة & 0 \\
\hline دقائق & زمن الجزء التمهيدي & 7 \\
\hline • إ دقيقة & زمن الجزء الرئيسي & V \\
\hline 0 دقائق & زمن الجزء الختامي & $\wedge$ \\
\hline
\end{tabular}

محتوي البرنامج الترويحي الرياضي المقترح: لتحقيق الهدف من البرنامج تم وضع محتوي البرنامج في صورة مجموعة من الوحدات التي تهدف إلي تحسين احدى مهارات الجمباز الايقاعي وتم تقسيم محتوي

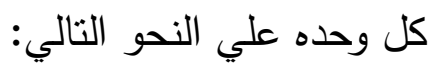

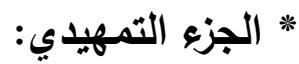
يهدف هذا الجزء إلي إعداد وتهيئة الطالبات بدنيا ونفسيا وفسيولوجيا وإدخال روح المرح والسرور والمشاركة الفعالة في البرنامج ،ويحتوي علي مجموعة من الألعاب الترويحية الرياضية تؤدي في صورة فردية أو جماعية ،ومدة هذا الجزء ( • () دقائق. 


\section{* الجزء الرئيسي:}

يهدف هذا الجزء بشكل اساسي إلي تعلم احدى مهارات الجمباز الايقاعي (الدحرجه الامامية،الوقوف على اليدين ) ،ويحتوي علي مجموعة من الألعاب الترويحية الأكثر نشاطا وحركة والتي تخدم المهارات وتعلمها علي لتحقيق هدف كل وحده ،ومدة هذا الجزء (•r) دقبقة.

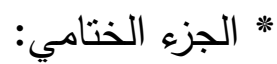

يهدف هذا الجزي إلي اعادة الطالبات لحالتهم الطبيعية بعد ممارسة محتوي الوحدة من خلال التهيئة والاسترخاء مع الحفاظ علي حالة السعادة والسرور للطالبات كويحتوي علي مجموعة من التمارين والألعاب الترويحة التي تحقق الهدف ،ومدة هذا

الجزء (0) دقائق.

الدراسة الاستطلاعية الثانية: قامت الباحثة بإجراء دراسة استطلاعية علي عينة قوامها (• (1) طالبات من مدرسه التجريبيه للغات بمحافظة الاقصر تم اختيارهم من مجتمع البحث وخارج عينة البحث الاساسية حيث تم تطبيق بعض اجزاء من وحدات البرنامج الترويحي الرياضي

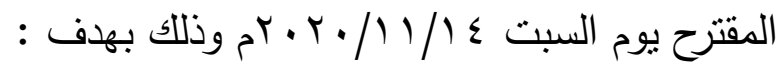
ا - التعرف علي مدي مناسبة البرنامج لعينة البحث. r- التعرف علي مدي ملائمة الفترة الزمنية المحددة لوحدات البرنامج. r- اكتشاف المشكلات والصعوبات التي قد تحدث اثثاء النطبيق. ؟- اعداد الادوات والاجهزة اللازمة لتطبيق البرنامج. ه- التأكد من توافر عوامل الأمن والسلامة اثثاء التطبيق. وقد اسفرت الدراسة عن ما يلي: 1- التأكد من مناسبة البرنامج مع عينة البحث. r- تم اعداد الادوات والاجهزة اللازمة للنطبيق والتأكد من صلاحيتها للتطبيق. r- تحديد الفترة الزمنية المناسبة لتطبيق البرنامج. 
ع - تعديل واستبعاد بعض الالعاب لعدم تتاسبها مع عينة البحث. 0- اختيار وتدريب المساعدين في تطبيق البرنامج. وبذلك أصبح البرنامج الترويحي الرياضي المقترح في صورته النهائية مرفق(V) ،والبرنامج الزمني لنطبيق البحث يتضح من خلال جدول ( · ( ) جدول(^) البرنامج الزمني لتطبيق البحث

\begin{tabular}{|c|c|c|}
\hline التوقيت & الاجراء & 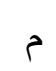 \\
\hline 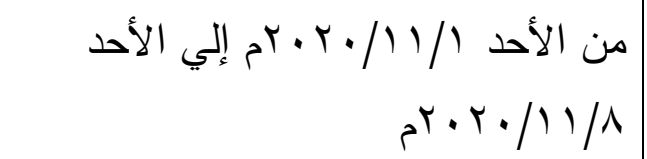 & الدراسة الاستطلاعية الأولي & 1 \\
\hline 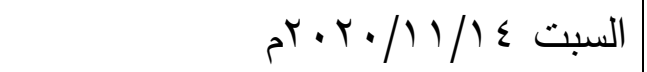 & الدراسة الاستطلاعية الثانية & r \\
\hline 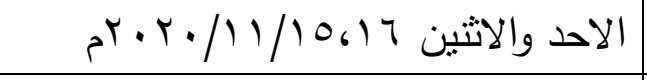 & القياسات القبلية & r \\
\hline 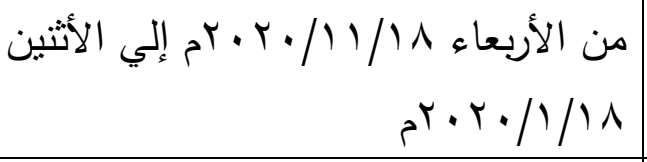 & 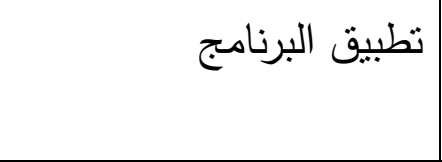 & $\varepsilon$ \\
\hline 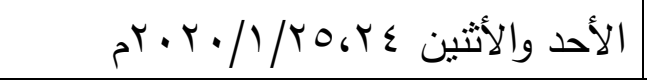 & القياسات البعدية & 0 \\
\hline
\end{tabular}

قامت الباحثة بإجراء القياسات القبلية لعينة البحث الأساسية في المقياس المستخدم لقياس مهارتي الاحرجه الاماميه ومهارة الوقوف علي اليدين ،وذلك يومي

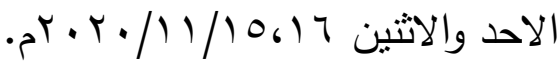

$$
\begin{aligned}
& \text { ثانيا: تطبيق البرنامج: }
\end{aligned}
$$

قامت الباحثة بنطبيق وحدات البرنامج الترويحي الرياضي المقترح مرفق (V)

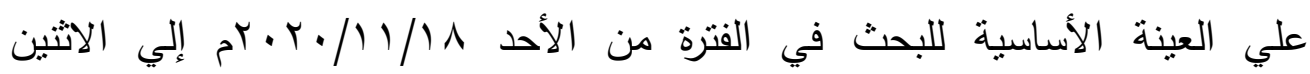




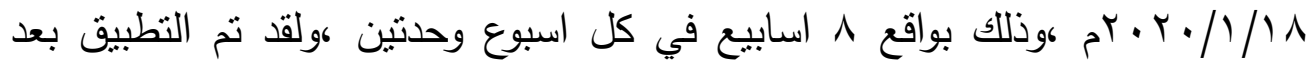
اليوم الدراسي بعد موافقة إدارة المدرسة. واولياء الامور • ثالثا: القياسات البعدية:

بعد الانتهاء من تطبيق البرنامج قام الباحث بإجراء القياسات البعدية يومي

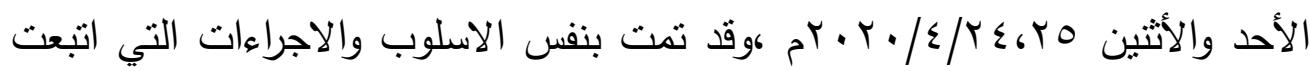
في القياسات القبلية. المعالجات الاحصائية المستخدمة في البحث: اعتمدت الباحثة علي الاساليب الاحصائية المناسبة لتطبيق البحث وهي:

$$
\text { - المستوسط. }
$$

\section{عرض النتائج ومناقشتها وتفسيرها}

تحقيقاً لأهدف البحث وتحقيقاً لفروض البحث وفي حدود ما توصلت إليه الباحثة من بيانات من خلا التحليل الإحصائي تحاول الباحثة عرض النتائج وتفسيرها ومناقشتها.

توجد فروق دالة إحصائيا بين متوسط القياسين القبلي والبعدي في الصفات البدنيه الخاصه برياضه الجمباز الايقاعي لعينة البحث لصالح القياس البعدي. عرض النتائج ومناقشتها:

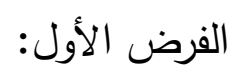

- - توجد فروق دالة إحصائيا بين القياسين القبلى والبعدى على مستوى الصفات البدنية لعينة البحث. 
مناقشثة النتائج:

- مناقشة نتائج الفرض الأول

يتضح من نتائج جدول (ع) وجود فروق دالة إحصائياً عند مستوى (0...) بين متوسطي درجات القياسين القبلي والبعدي في القدرات البدنية قيد البحث لصالح منتسط

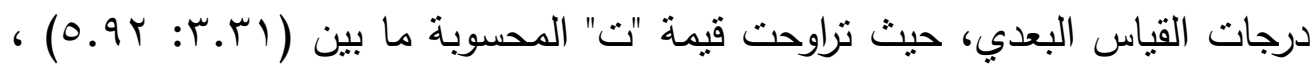

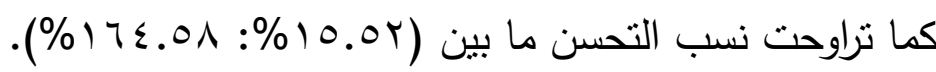

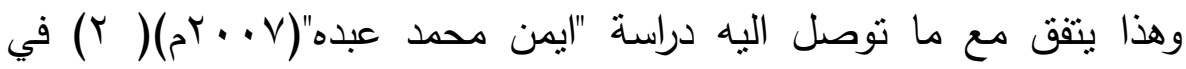

$$
\text { دراسته التى تهدف الي مني }
$$

تصميم برنامج تدريبى منكامل لتحسين مستوى الاداء المهارى والبدنى للمبندئين فى رياضة الجمباز ، واستخدم الباحث المنهج التجريبي بتصميم مجموعتين واحده تجريبية والاخري ضابطة ، وبلغ قوام عينة البحث (1 ( )مبتدئ واستخدم (شريط قياس - ساعة ايقاف - جنيوميتز)كأدوات لجمع البيانات كانت من اهم النتائج التى توصلت اليها الباحثة:

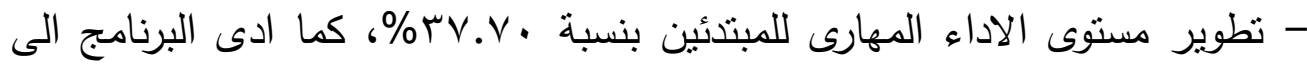
تطوير مستوى الصفات البدنبة الخاصة للمبتدئين فى الجمباز بنسبة نراوحت بين

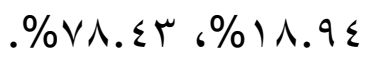

وتقسر الباحثة هذه النتائج التى اظهرت إن ممارسة الجمباز الايقاعي خلال برنامج ترويحي وتلبى من خلالها حاجات ورغبات المشاركين فى الأنشطة الترويحية

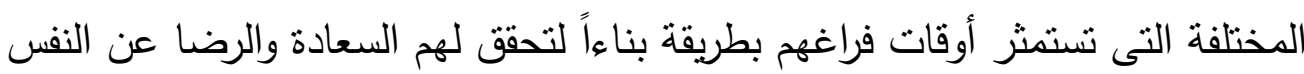
كهدف اسمى، كما أن لها دور هام فى نمو العديد من جوانب الفرد البدنية والنفسية والاجتماعية والخلقية والمعرفية كأهداف ضمنية وتهتم المؤسسات الترويحية المختلفة بتصميم البرامج الترويحية حيث نتبع الأسس العلمية وتواكب الاتجاهات التربوية الحديثة. 
وتثير الباحثة الى ان بعض الدراسات قد سجلا تحسن في الصفات البدنية الخاصة برياضة الجمباز الايقاعي سواء كان بعد التمرين مباشرة كاستجابة او بعد برنامج

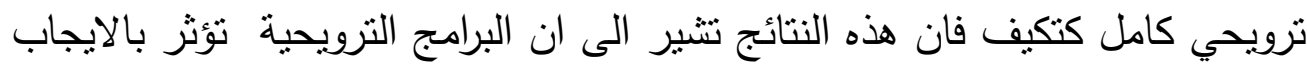

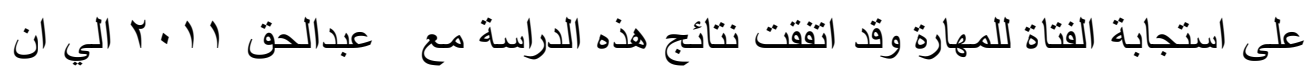
رياضه الجمباز من الرياضات ذات الاهميه الكبري في برامج التربيه الرياضيه والتي هده

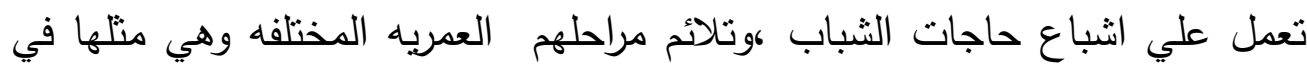
ذللك مثل اي نشاط فردي اخر، حيث تعمل علي تزويد الفرد بالمهارات والتى تستمر

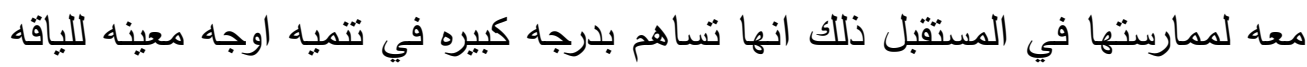
البدنيه وتطويرها والارتقاء بها(^)

وبذللك يتحقق جزئيا صحة الفرض الاول الذي ينص علي :

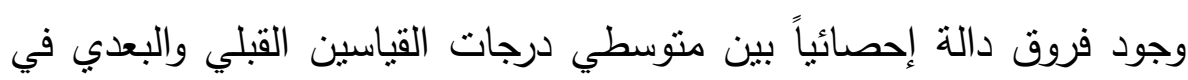
القدرات البدنية قيد البحث لصالح متوسط درجات القياس البعدي. - تفسير نتائج الفرض الثاني

يتضح من نتائج جدول (0) وجود فروق دالة إحصائياً عند مستوى (0...) بين منوسطي درجات القياسين القبلي والبعدي في مهارات الجمباز الايقاعي قيد البحث لصالح متوسط درجات القياس البعدي، حيث بلغت قيمة "ت" المحسوبة ما بين

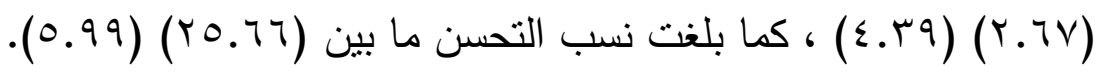
وهذا يتفق مع ما توصل اليه نتائج العديد من الدراسات العربية والأجنية على أهمية

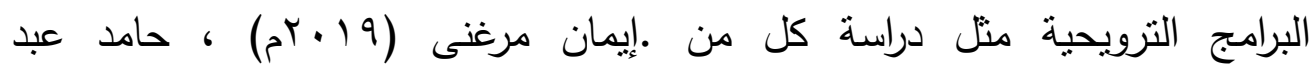

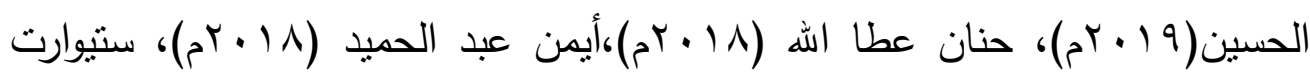

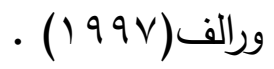


وتتشير الباحثة الى ان بعض الدراسات قد سجلت تحسن في الانشطة الرياضيه من خلا ادارج برامج ترويحيه وقد اظهرت نتائج هذه الدراسة حدوث تحسن في مهارة الدحرجه الامامية والوقوف على اليدين في الجمباز الايقاعي. وبذلك يتحقق جزئيا صحة الفرض الثاني الذي ينص علي :

وجود فروق دالة إحصائياً عند مستوى بين متوسطي درجات القياسين القبلي والبعدي في مهارات الجمباز الايقاعي قيد البحث لصالح متوسط درجات القياس البعدي مي مئي

\section{- الاستتناجات:}

في ضوء اهداف البحث وفروضه وفي حدود عينة البحث وخصائصها امكن للباحثنان التوصل الى الاستتناجات التالية:

1- أهمية البرامج الترويحية لدورها فى تتمية وتطوير شخصية الفرد

r-ثاثير البرنامج بالايجاب علي المستوى البنني والمهاري للفتيات

r-اظهرت النتائج ان ممارسة الانشطة الرياضية من خلال برنامج ترويحي يعمل علي كسر عامل الملل وتعلم المهارة بشكل افضل

- التوصيات:

استتاد الى النتائج التى نم التوصل اليها من البحث الحالى ، وفي ضوء ما امكن مناقشته هذه النتائج توصي الباحثة بما يلي:

ا.الاهتمام البرامج الترويحية لتاثيرتها الايجابية على تحسين مستوى احدى مهارات

$$
\text { رياضة الجمباز الايقاعي قيد البحث. }
$$

r.ضرورة الاهتمام بالانثطة الترويحية لتاثيرتها الايجابية على تطوير شخصية الفرد. r. تصميم البرامج الترويحية حيث تتبع الأسس العلمية وتواكب الاتجاهات التربوية الحديثة 
ع.بوصي الباحتان أن ممارسة النشاط الرياضي من خلا برامج ترويحية تؤدى إلى تفريغ الطاقات العدوانية في اللعب بشكل غير منحرف ○. يعتبرالجمباز الايقاعي من الأنشطة الهامة التى تعطى التقة بالنفس والثعور بالسعادة والسرور ، كما أنه يعمل على تتمية بعض القدرات الحركية ويسهم بدرجة كبيرة فى الإرتقاء بالتذوق الفنى والجمالى. 1- ضرورة وجود برامج مقننة ومدروسة ومبنية على أسس علمية سليمة في المؤسسات التعليمية المختلفة لما لها من أثز إيجابي في تعليم المهارات الرياضيه ـ

\section{المراجــ}

اولا: المراجع العربية : الم:ابة

1- اميرة امين نصر الدين سليمان:" فاعلية برنامج للتعبير الحركى على تحسين اضطراب السلوك"، رسالة ماجستير ، حلوان، 9 1 • بم.

ץ- ايمن محمد عبده عبد العزيز :" تأثنير برنامج تدريبي مقترح على مستوى أداء المبتدئين فى رياضة الجمباز "، رسالة ماجستير ، غير منشوره، تربية رياضية

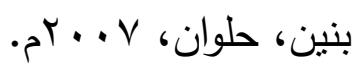

r-رانيا عبد الهادى عبد الهادى حسانين:" تأثير برنامج للتمرينات التكنيكية الايقاعية على القدرات الايقاعية ومستوى الأداء للجملة الحركية فى الرقص

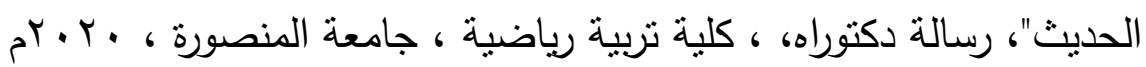
ع - محمود اسماعيل طلبه ابراهيم:" سيكولوجية الترويح وأوقات الفراغ"، اسلاميك

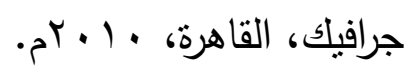

ه-مرام شوقى عبد الفتاح:" تأثير برنامج ترويحى مقترح على مستوى الضغوط

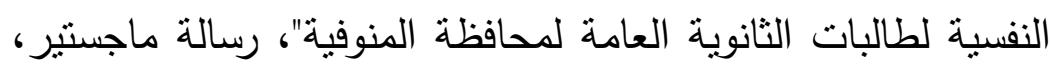

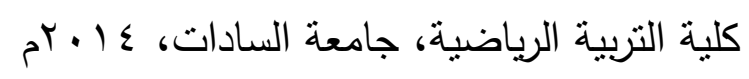


7- كمال عبد الرحمن درويش ،محمد محمد الحمامى: "روية عصرية للترويح

$$
\text { وأوقات الفراغ"، مركز الكتاب للنشر ، القاهرة، V . - rم. }
$$

V-كمال عبد الرحمن درويش ،أمين أنور الخولى:" الترويح وأوقات الفراغ (التاريخ والفلسفة الإجتماعيات البرامج والأنشطة)"، دار الفكر العربى، القاهرة

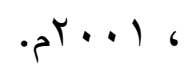

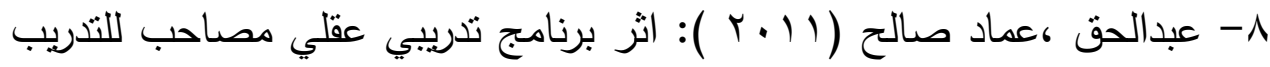
المهاري في تحسين مستوى الاداء المهاري في رياضه الجمناستلك لطلبه كليه التربيه الرياضيه مجله الجامعه الاسلاميه (سلسله الدراسات الانسانيه) المجلد 9 (،العدد ا. . 9- فاتن طه ابراهيم البطل ،عنايات محمد احمد فرج(ع . . ץ):التمرينات الايقاعيه

$$
\text { (الجمبازالايقاعي)والعروض الرياضيه. }
$$

• مهارات كرة اليد للاطفال المعاقين ذهنياً القابلين للتعلم، رسالة ماجستير ، كلية التربية الرياضية للبنات، الاسكندرية، 9 1 • بم. | - امد على عبد الحسين:" برنامج ترويحى لتحسين الوعى الصحى لدى أطفال مرضى السكر من و-r اسنة فى العراق"، رسالة دكتوراه، تربية رياضية

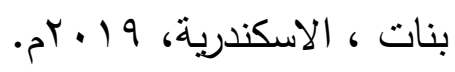

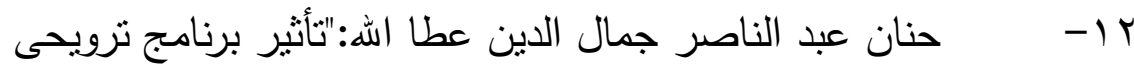
باستخدام الألعاب الصغيرة لتحسين المرونة النفسية للتلميذات الصم والبكم بالحلقة الثانية من التعليم"، رسالة دكتوراه، تربية رياضية بنات،

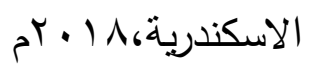


"r - رانيا مرسى ابو العباس وأحمد محمد ابو اليزيد و شيماء محمد على : دراسة تحليلية لمهارات التعبير الحركى فى بطولة العروض الرياضية للكليات

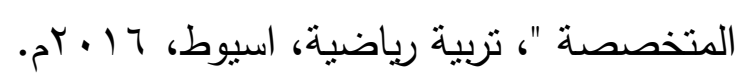

ع ا - عفاف عبد الرحمن زهران :" العلاقة بين سمات الثخصية واللياقة البدنية وبين التفوق فى التعبير الحركى "، رسالة دكتوراه، كية تربية رياضية

$$
\text { بنات، اسكندرية، جامعة حلوان، ، · } 91 \text { (م. }
$$

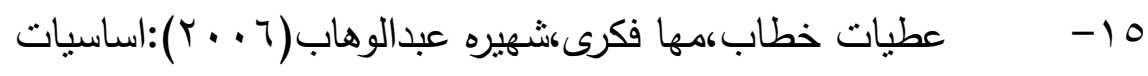

التمرينات والتمرينات الايقاعيه ،ط ( كمركز الكتاب للنشر ،القاهرة

\section{ثانيا المراجع الاجنبية}

Virou: On the usabitiy and dike ability of uintual reality

Educational the case of v-EGAGA, 17-Game bas computes and Educational .(2008 